\title{
Polymerization of Methyl Methacrylate Initiated by Arylsulfinic Acids
}

\author{
Toshio Watanabe, Kazuyoshi Sakai, Rikiya Sato, \\ and Makoto TAKEISHI ${ }^{\dagger}$ \\ Department of Materials Science and Engineering, Yamagata University, \\ Yonezawa, Yamagata 992, Japan \\ (Received October 1, 1996)
}

\begin{abstract}
Arylsulfinic acids such as benzenesulfinic acid (BSA) initiated the polymerization of methyl methacrylate (MMA) without oxidizing agents. Hydroquinone and 1,1-diphenyl-2-picrylhydrazyl had no inhibitory effect on the polymerization, indicating that the polymerization proceeded via a non-radical process. The rate of polymerization was found to be proportional to $[\mathrm{BSA}]^{0.98}$ and $[\mathrm{MMA}]^{0.99}$. The polymerization was greater in less polar solvents than in polar solvents. On the basis of the experimental results obtained, an ionic mechanism was proposed, in which a Michael-type addition of the arylsulfinic acid to MMA leads to the polymerization. KEY WORDS Zwitterion Polymerization / Sulfinic Acid / Methyl Methacrylate / Michael Addition /
\end{abstract}

Redox polymerization using benzenesulfinic acid is of industrial importance and many patents relevant to this technology have been issued. ${ }^{1-3}$ Sulfinic acids generally behave as reducing agents and are known to initiate redox polymerization when combined with an oxidant. The polymerization of vinyl monomers initiated by a sulfinic acid was first reported by Hagger. ${ }^{4}$ Marvel et al. tried a copolymerization of styrene with butadiene using 1alkanesulfinic acids under air, in which the effects of ferrous and ferric ions and dodecyl mercaptan were investigated. ${ }^{5}$ Hachihama et al. studied polymerization of ethyl acrylate in the presence of benzenesulfinic acid with oxygen or with benzoyl peroxide ${ }^{6}$ and observed that the sulfinic acid can solely initiate the polymerization. A polymerization of methyl methacrylate initiated by benzenesulfinic acid in the absence of oxidants has been reported also by Overberger et al., in which a radical species formed by decomposition of the unstable sulfinic acid was assumed to be responsible for initiation. The detailed mechanism, however, remained unclear because hydroquinone did not inhibit the polymerization and the rate was first-order in the initiating agent. ${ }^{7} \mathrm{~A}$ polymerization initiated by $p$-toluenesulfinic acid with benzoyl peroxide has also been reported to proceed in the presence of hydroquinone. ${ }^{8}$ In the course of our studies also, a polymerization of methyl methacrylate initiated by benzenesulfinic acid has been found to proceed without. an oxidant. ${ }^{9}$

These peculiar experimental observations induced us to elucidate the mechanism of polymerization initiated by sulfinic acids. The present paper shows evidence for a non-radical polymerization process.

\section{EXPERIMENTAL}

\section{Material}

Benzenesulfinic acid (BSA) was prepared as previously reported. ${ }^{9}$ The crystalline substance formed was collected by filtration and used without further purification, yield $69 \%, \mathrm{mp} 73.5-75^{\circ} \mathrm{C}$ (lit. ${ }^{10} 74-76^{\circ} \mathrm{C}$ ). $p$-Toluenesulfinic acid (TSA) was prepared in a similar manner, yield

† To whom correspondence should be addressed.
$77.4 \%, \mathrm{mp} 84-86^{\circ} \mathrm{C}$ (lit. ${ }^{11} 84-85^{\circ} \mathrm{C}$ ). The sulfinic acids were stored under nitrogen at $5^{\circ} \mathrm{C}$. Methyl methacrylate (MMA) was distilled according to the usual manner. Other special grade reagents and solvents were used without further purification.

\section{Polymerization}

Required amounts of MMA and a sulfinic acid were put in a brown glass tube. The tube was cooled in an ice bath, internal air was replaced with argon, and the polymerization was carried out by placing the tube in a bath thermostated at $30^{\circ} \mathrm{C}$. At certain periods the reaction mixture was poured into methanol, and the precipitated polymer was filtered off and dried in vacuo. Conversion was determined by weighing the polymer.

\section{Measurements of Molecular Weight}

Molecular weight of the polymer was determined by means of gel permeation chromatography (GPC) (column: Shodex KD-80M, eluent: dimethylformamide (DMF) containing $0.01 \mathrm{M} \mathrm{LiBr}, 40^{\circ} \mathrm{C}$ ). Number- and weight-average molecular weights $\left(\bar{M}_{n}\right.$ and $\left.\bar{M}_{w}\right)$ were calibrated with standard polystyrenes.

\section{Equimolar Reaction of Bezenesulfinic Acid with MMA}

The procedure was similar to that for the polymerization. MMA (0.47 mmol), BSA (0.47 mmol), and dimethyl sulfoxide (DMSO)- $d_{6}(0.6 \mathrm{ml})$ were taken in an NMR tube and it was purged with nitrogen under cooling at $0^{\circ} \mathrm{C}$. The reaction was started by placing the tube in a bath thermostated at $30^{\circ} \mathrm{C}$ and followed by monitoring the vinyl proton of MMA on a NMR spectrometer.

\section{RESULTS AND DISCUSSION}

\section{Effect of Hydroquinone}

We postulated a non-radical mechanism for polymerization of MMA initiated by BSA without an oxidizing agent. ${ }^{9}$ The results of bulk polymerization of MMA with BSA and with TSA are shown in Figure 1. The rate with TSA was greater than that with BSA; the reason is described below in discussion for a reaction mechanism. 


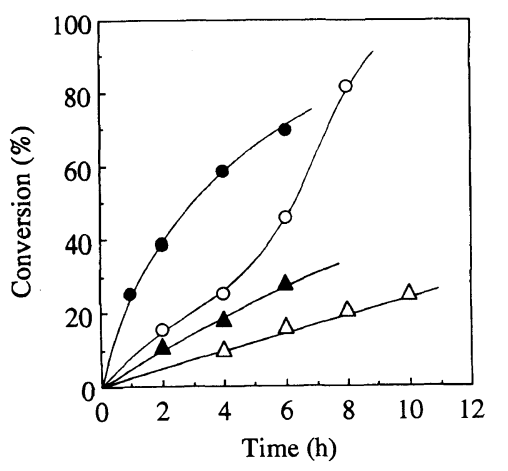

Figure 1. Polymerization of MMA with sulfinic acids in the presence of hydroquinone. MMA $9.4 \mathrm{mmol}$; (O) TSA $0.2 \mathrm{mmol}$, hydroquinone $0.4 \mathrm{mmol}$; (O) TSA $0.2 \mathrm{mmol}$, hydroquinone nil; (A) BSA $0.2 \mathrm{mmol}$, hydroquinone $0.4 \mathrm{mmol}$; $(\triangle)$ BSA $0.2 \mathrm{mmol}$, hyroquinone nil.

Hydroquinone did not inhibit but accelerated the polymerization with both sulfinic acids. In the case with TSA, a marked increase in the rate was observed at higher conversion above $30 \%$, but in the presence of hydroquinone, such an increase was not observed up to $70 \%$ conversion.

\section{Effect of 1,1-Diphenyl-2-picrylhydrazyl (DPPH)}

Hydroquinone is not always an effective inhibitor for radical polymerization. ${ }^{12,13}$ For example, it inhibits the polymerization of butyl acrylate with benzoyl peroxide but has little effect on the polymerization initiated by azobisisobutyronitrile. ${ }^{14}$ This inhibition is not due to hydrogen transfer from hydroquinone to the propagating chain end but due to the hydrogen transfer to the oxygen-centered initiating radical species from the former initiator. Benzoquinone can not be used for this purpose because sulfinic acids form adducts with it. ${ }^{15}$

In order to distinguish the initiating species, the effect of DPPH on the polymerization was also examined. No induction period was observed in the presence of the radical scavenger (Figure 2) and the polymerization proceeded slightly faster than in its absence. These observations also suggest that this polymerization is different from usual radical polymerization.

Table I shows that increase in DPPH concentration enhanced conversion to a certain extent but further increase resulted in a slight reduction of the conversion. We previously observed a very similar phenomenon in thiophenol-initiated polymerization of MMA with this radical scavenger or galvinoxyl. ${ }^{16}$ Increased amounts of DPPH also caused a marked decrease in molecular weight of the polymer and narrowed its distribution.

A decrease in molecular weight of polymers formed in ordinary chain reaction polymerization results usually from depressed propagation and/or accelerated termination. In such a case the rate of polymerization, or the conversion, decreases. In our case, however, the decrease in molecular weight of the polymer was accompanied by an enhanced conversion (Table I) as observed in radical polymerization when concentration of the initiator is increased. Therefore, DPPH seems to promote the initiation by BSA as we described for the polymerization of MMA initiated by thiophenol, ${ }^{16}$ in which hydrogen transfer from the initiator to this radical scavenger was assumed to yield initiating species. An observation that

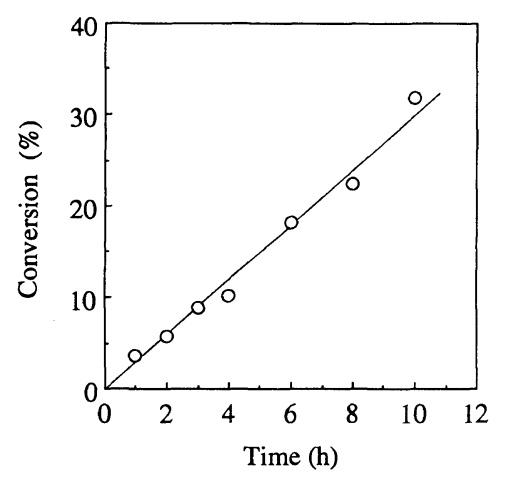

Figure 2. Polymerization of MMA with benzenesulfinic acid. MMA $9.4 \mathrm{mmol}$; BSA $0.2 \mathrm{mmol}$; DPPH $0.2 \mathrm{mmol}$.

Table I. Effect of DPPH ${ }^{a}$

\begin{tabular}{|c|c|c|c|c|c|}
\hline DPPH & Conversion & & & & \\
\hline $\mathrm{mmol}$ & $\%$ & & & & \\
\hline 0 & 25.6 & 299 & 1.51 & 203 & 1.92 \\
\hline 0.1 & 31.1 & 93 & 1.62 & 60 & 1.74 \\
\hline 0.2 & 33.6 & 66 & 1.49 & 45 & 1.72 \\
\hline 0.4 & 31.8 & 62 & 1.37 & 25 & 1.63 \\
\hline 0.8 & 28.8 & 47 & 1.27 & 18 & 1.62 \\
\hline
\end{tabular}

${ }^{\text {a }}$ Conditions: MMA $18.8 \mathrm{mmol}$; BSA $0.4 \mathrm{mmol}, 10 \mathrm{~h} .{ }^{\mathrm{b}} \mathrm{THF}$ was used as the eluent for GPC.

Table II. Effect of solvent on the polymerization of MMA ${ }^{a}$

\begin{tabular}{lrrrr}
\hline \multirow{2}{*}{ Solvent } & \multicolumn{3}{c}{ Conversion } \\
\cline { 2 - 4 } & $\varepsilon^{b}$ & \multicolumn{1}{c}{$\%$} & $\bar{M}_{n} \times 10^{-3}$ & $\bar{M}_{w} / \bar{M}_{n}$ \\
\hline Benzene & 2.3 & 20.4 & 199 & 1.70 \\
Ethyl acetate & 6.0 & 18.7 & 194 & 1.62 \\
Tetrachloroethane & 8.2 & 16.4 & 191 & 1.58 \\
Acetonitrile & 37.5 & 12.1 & 181 & 1.62 \\
DMF & 36.7 & 6.6 & 1680 & 2.26 \\
DMSO & 48.9 & 2.8 & $>2000^{\mathrm{c}}$ & -
\end{tabular}

a Conditions: MMA $18.8 \mathrm{mmol}$; BSA $0.4 \mathrm{mmol}$; solvent $2 \mathrm{ml}$, $10 \mathrm{~h}$. ${ }^{\mathrm{b}}$ Dielectric constant. ${ }^{\mathrm{c}}$ The exclusion limit of the column used for GPC analysis was $2 \times 10^{6}$.

the characteristic UV-Vis absorption bands of DPPH disappeared on addition of BSA suggests that the reaction between them participates in the initiation of the polymerization, although the detailed mechanism is still unclear. As shown in Table I, GPC analysis gave different values of molecular weight distribution for one sample depending on the eluent: for example, 1.27 and 1.62 with DMF ( $\mathrm{LiBr} 0.01 \mathrm{M}$ ) and with tetrahydrofuran (THF), respectively, in the presence of DPPH $(0.8 \mathrm{mmol})$. This relatively narrow distribution would stem from the decreased molecular weight.

\section{Effect of Polarity of Solvents}

Table II shows the results of solution polymerization with various solvents. The polymerization was accelerated in less polar media. As can be seen in comparison with the results in Figure 1, the rate of polymerization in benzene was, though diluted with the solvent, almost the same as that of bulk polymerization. The conversion decreased markedly in much polar DMF and DMSO, 


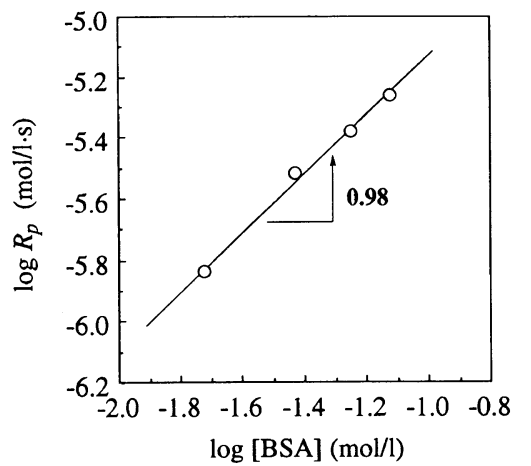

Figure 3. Dependence of the rate of polymerization on BSA concentration. MMA $9.4 \mathrm{mmol}$; benzene $4 \mathrm{ml}$.

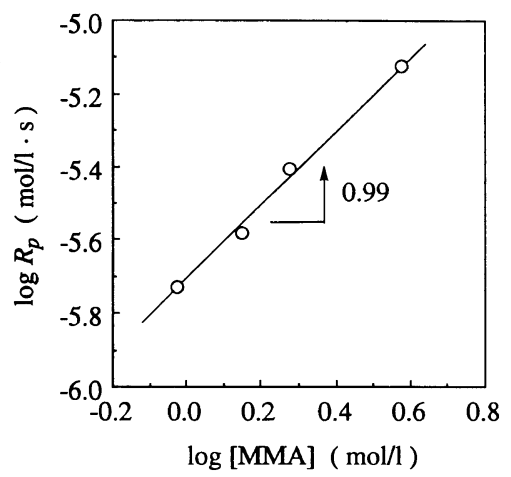

Figure 4. Dependence of the rate of polymerization on MMA concentration. BSA $37.3 \mathrm{mmol}$; benzene + monomer $5 \mathrm{ml}$.

while molecular weight of the polymer formed in the solvents increased. The pronounced change of the polymerization rate depending on polarity of the solvent is suggestive of ionic properties of the reactions involved. If this polymerization proceeds through an ionic chain reaction, all the initiation, propagation, and termination must highly depend on polarity of the reaction medium; consequently, each rate and molecular weight of the polymer will change, accordingly. The decrease in molecular weight led to narrowing its distribution. The polymers obtained both in polar and in less polar solvents were rich in syndiotacticity (syndiotactic triad: $65 \%$ in DMF, $66 \%$ in benzene) as the polymers formed by anionic polymerization in polar media and by radical polymerization.

\section{Reaction Order}

Polymerization rates were calculated on the basis of time-conversion plots. The initial rate was first-order with respect to both the initiator and the monomer concentration as shown in Figures 3 and 4. The firstorder dependence of the rate on the initiator concentration has already been observed in BSA-initiated vinyl polymerizations. ${ }^{6}{ }^{6}$ Since usual radical polymerization follows square-root kinetics with respect to initiator, the observed reaction order also is suggestive of a non-radical mechanism for this polymerization.

\section{Polymerization Mechanism}

The polymerization data obtained so far all suggest that the reaction proceeds through a non-radical process. In addition, ESR measurements using 2-methyl-2-nitrosopropane and nitrosodurene as spin traps indicated the absence of radical species under the conditions applied. It was found that the polymerization does not occur with sodium salt of BSA; therefore, the sulfinate anion is unlikely to initiate the polymerization and acidic the form of BSA seems necessary for the initiation. On the other hand, BSA has been reported to undergo polar addition of Michael-type to $\alpha, \beta$-unsaturated carbonyl compounds. ${ }^{10,17,18}$ To our interest, polymers with high molecular weight were formed even in the presence of a large excess of the acid ( $200 \mathrm{~mol} \%$ to monomer) as shown in the previous paper ${ }^{9}$ and discussed below with Table III. Accordingly, we postulate a possible nonradical mechanism for this polymerization as shown in Scheme 1 , in which an initiating zwitterion is formed via complexation of BSA with the monomer and the propagation proceeds in a manner similar to zwitterion polymerization. Aromatic ring protons of the initiation attached to the polymer end were detected in the NMR spectra, but accurate integration was difficult because of their small ratio in the polymer.

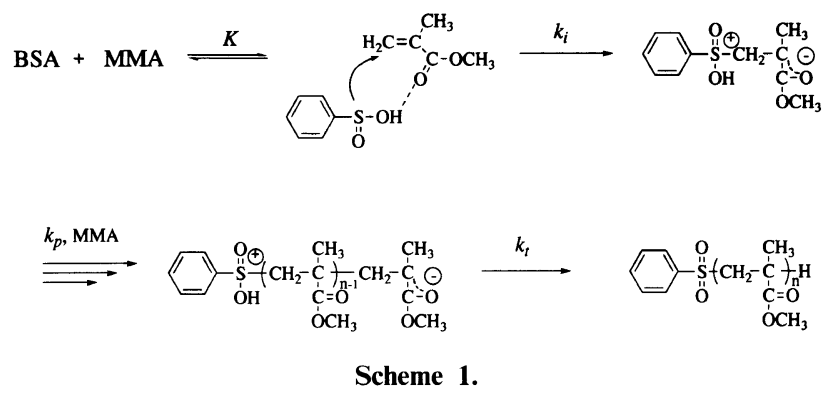

The complexation to yield initiating species is rapid. Accordingly, a steady-state can be assumed, because molecular weights of the polymers did not increase at higher conversions indicating that the polymerization has no living nature and the concentration of the propagating ionic species is therefore constant. Under usual conditions of $[\mathrm{MMA}] \gg[\mathrm{BSA}]$ the polymerization rate is given by eq 1 .

$$
R_{\mathrm{p}}=\frac{k_{\mathrm{p}} k_{\mathrm{i}} K[\mathrm{BSA}][\mathrm{MMA}]^{2}}{k_{\mathrm{t}}(1+K[\mathrm{MMA}])}
$$

For the case of $1 \ll K$ [MMA] the rate is approximated as eq 2, which is coincident with the experimental results (Figures 3 and 4).

$$
R_{\mathrm{p}}=\frac{k_{\mathrm{p}} k_{\mathrm{i}}}{k_{\mathrm{t}}}[\mathrm{BSA}][\mathrm{MMA}]
$$

In a case where polymerization is initiated by direct addition of BSA to MMA, kinetic analysis predicts that the rate is second-order with respect to the concentration of MMA. Such a zwitterion polymerization that follows second-order kinetics with respect to monomer concentration has been reported, in which pyridine initiates the polymerization of nitroethylene. ${ }^{19}$ In usual zwitterion polymerizations, kinetic rates exceed first-order with respect to concentration of the monomer. ${ }^{20}$ In some cases, however, the rates become first-order in the monomer concentration depending on the reaction conditions. ${ }^{21}$

Nucleophilic addition of arylsulfinic acids to phenyl acrylate is accelerated by introducing electron-donat- 


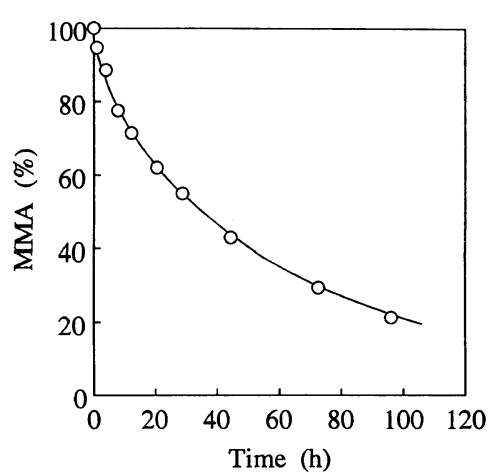

Figure 5. The reaction of MMA with equimolar BSA. MMA $0.47 \mathrm{mmol}$; BSA $0.47 \mathrm{mmol}$; DMSO- $d_{6} 0.6 \mathrm{ml}, 30^{\circ} \mathrm{C}$.

Table III. Polymerization of MMA in polar solvents

\begin{tabular}{|c|c|c|c|c|}
\hline \multirow{2}{*}{ Solvent } & \multirow{2}{*}{$\frac{\mathrm{BSA}}{\%}$} & \multirow{2}{*}{$\frac{\text { Conversion }}{\%}$} & \multirow{2}{*}{$\bar{M}_{n} \times 10^{-3}$} & \multirow{2}{*}{$\bar{M}_{w} / \bar{M}_{n}$} \\
\hline & & & & \\
\hline \multirow[t]{4}{*}{$\mathrm{DMF}^{\mathrm{a}}$} & 10 & 11.4 & 542 & 1.50 \\
\hline & 20 & 15.8 & 316 & 1.58 \\
\hline & 50 & 33.5 & 169 & 1.56 \\
\hline & 100 & 52.9 & 54 & 1.36 \\
\hline \multirow[t]{5}{*}{$\mathrm{DMSO}^{\mathrm{b}}$} & 10 & 4.7 & - & - \\
\hline & 20 & 13.1 & 1,582 & 2.31 \\
\hline & 50 & 15.6 & 902 & 1.92 \\
\hline & 100 & 24.6 & 361 & 1.74 \\
\hline & 200 & 37.1 & 174 & 1.58 \\
\hline
\end{tabular}

${ }^{\mathrm{a}}$ Conditions: MMA $9.4 \mathrm{mmol}$, DMF $2 \mathrm{ml}, 18 \mathrm{~h} .{ }^{\mathrm{b}}$ Conditions: MMA $1.88 \mathrm{mmol}$; DMSO $2 \mathrm{ml}, 24 \mathrm{~h}$.

ing substituents into the aromatic ring of the acids. ${ }^{17}$ Therefore, the observation that the polymerization with TSA was faster than that with BSA (Figure 1) can be interpreted on the basis of enhanced addition of TSA to the monomer and can also be evidence for the assumed mechanism. However, this ionic mechanism is merely a speculated one on the basis of experimental results. Since propagation of ordinary anionic chain ends is instantaneously terminated in the presence of a protonic acid, formation of the polymer seems difficult. Although we have no definite information to explain how the anionic end is protected from the termination to yield the polymer, proper stabilization by the sulfur-centered cation is expected.

\section{Polymerization in Polar Solvents}

As shown in Table II, the conversions were low in polar solvents such as DMF and DMSO. This is probably because the equilibrium of complex formation between BSA and MMA in Scheme 1 shifts to dissociation in polar media, and consequently, the Michael-type addition for initiation of the polymerization is retarded. An equimolar reaction of BSA with MMA was carried out to examine the Michael-type addition in DMSO. The reaction was followed by measuring the decrease of vinyl proton of MMA on a NMR spectrometer at $30^{\circ} \mathrm{C}$. The rate of disappearance of the vinyl group of MMA was relatively slow in the polar solvent (Figure 5). BSA reacts with aryl acrylates to yield Michael-type adducts. ${ }^{17}$ Nevertheless, in the case of MMA, only the polymer was formed even with excess amounts of BSA up to $200 \mathrm{~mol} \%$
Table IV. Accelaration by zinc chloride ${ }^{\mathrm{a}}$

\begin{tabular}{|c|c|c|}
\hline $\mathrm{ZnCl}_{2}$ & Time & Conversion \\
\hline $\mathrm{mmol}$ & $\mathrm{h}$ & $\%$ \\
\hline 0 & 6 & 2.6 \\
\hline 0.8 & 6 & 3.9 \\
\hline 0.8 & 10 & 6.2 \\
\hline 8.0 & 10 & 22.3 \\
\hline
\end{tabular}

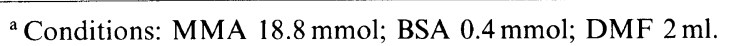

Table V. Inhibition by $p$-toluenesulfonic acid ${ }^{\mathbf{a}}$

\begin{tabular}{ccccc}
\hline$p$-Toluenesulfonic acid & & Conversion & & \\
\cline { 1 - 1 } mmol & & $\bar{M}_{n} \times 10^{-3}$ & $\bar{M}_{w} / M_{n}$ \\
\hline 0 & 21.2 & 301 & \\
\hline 0.02 & 13.3 & 182 & 1.80 \\
0.04 & 12.2 & 196 & 1.62 \\
0.20 & 13.3 & 171 & 1.65 \\
\hline
\end{tabular}

${ }^{\text {a }}$ Conditions: MMA $18.8 \mathrm{mmol}$; BSA $0.4 \mathrm{mmol}, 8 \mathrm{~h}$.

(Table III). In the reaction of aryl acrylates, the nucleophilic addition of sulfinic sulfur to the carboncarbon double bond of the acrylates is followed by instantaneous protonation to yield the adducts. However, in the reaction of MMA, quite a number of the monomers add to the zwitterionic intermediate before the protonation, or termination, occurs. That is, the chain length of this chain reaction is long enough to yield a polymer. Increase in BSA concentration led to increase in conversion and decrease in molecular weight of the polymer because of the increased initiating species.

\section{Effect of Lewis and Protonic Acids}

As presented in Table IV, the conversion increased in the presence of zinc chloride. This acceleration by the Lewis acid can be explained by its complexation with both the propagating chain end and the monomer, in which the Lewis acid not only mediates propagation but also activates the monomer (Scheme 2). Similar acceleration is well known in radical polymerization. ${ }^{22}$

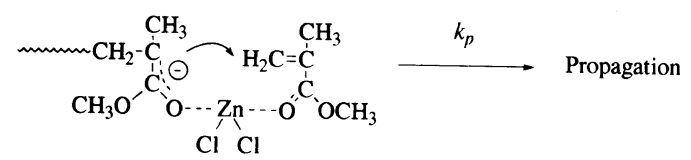

Scheme 2.

A protonic acid, $p$-toluenesulfonic acid, has been reported to accelerate a BSA-initiated vinyl polymerization. ${ }^{7}$ This protonic acid however retarded the polymerization in our case (Table V). Enhanced termination caused by increased proton is a possible explanation for this retardation. Another probable mechanism for the retardation is as follows: this protonic acid competes with BSA for the complex formation shown in Scheme 1 , reducing the yield of initiating species. The latter mechanism seems likely because hyperbolically decreasing conversion in Table $\mathrm{V}$ is suggestive of the complex formation. 
Polymerization of MMA with Sulfinic Acids

Table VI. Effect of oxygen and hydroquinone $\mathrm{a}^{\mathrm{a}}$

\begin{tabular}{|c|c|c|c|c|c|c|c|c|c|}
\hline \multirow{3}{*}{ Run } & \multirow{3}{*}{ Solvent } & \multirow{3}{*}{ Atmosphere } & \multirow{3}{*}{$\frac{\text { Time }}{\mathrm{h}}$} & \multicolumn{3}{|c|}{ HQ (nil) } & \multicolumn{3}{|c|}{ HQ (0.4 mmol) } \\
\hline & & & & Convn. & & & Convn. & & \\
\hline & & & & $\%$ & & & $\%$ & $M_{n} \times 10$ & $n_{w} / M_{n}$ \\
\hline 1 & $-^{b}$ & $\mathrm{Ar}$ & 6 & 16.5 & 412 & 1.80 & 28.2 & 195 & 1.94 \\
\hline 2 & - $^{\mathrm{b}}$ & Air & 6 & 2.9 & 107 & 1.49 & 32.3 & 181 & 1.70 \\
\hline 3 & Benzene & $\mathrm{Ar}$ & 9 & 18.4 & 185 & 1.59 & 26.3 & 134 & 1.56 \\
\hline 4 & Benzene & Air & 9 & 11.2 & 131 & 1.54 & 37.7 & 76 & 1.47 \\
\hline 5 & DMF & $\mathrm{Ar}$ & 6 & 2.6 & 1,221 & 1.65 & 2.2 & 1,174 & 1.62 \\
\hline 6 & DMF & Air & 6 & 7.2 & 327 & 1.74 & 0 & - & - \\
\hline
\end{tabular}

${ }^{\mathrm{a}}$ Conditions: MMA $9.4 \mathrm{mmol}$; BSA $0.2 \mathrm{mmol}$; solvent $1 \mathrm{ml} . \quad{ }^{\mathrm{b}}$ Bulk polymerization.

\section{Effect of Oxygen}

Since sulfinic acids have been used for redox polymerization in combination with oxygen, we examined the influence of oxygen on the BSA-initiated polymerization and results are presented in Table VI. In bulk polymerization the conversion markedly decreased under air compared to that under argon (Runs 1,2). A decrease in conversion under air was observed also in a solution polymerization in benzene (Runs 3,4). These results indicate that the redox system of BSA and oxygen did not work effectively in less polar media at $30^{\circ} \mathrm{C}$ and oxidized BSA could not initiate the non-radical polymerization. The inhibitory effect of oxygen disappeared in the presence of hydroquinone (Runs 2,4 ) probably because the oxidation of BSA is inhibited by the reductant. As described above with Figure 1, an acceleration by hydroquinone under argon was observed (Runs 1, 3). The rather small conversion in DMF was enhanced under air; therefore, the redox system seems effective in this polar solvent (Runs 5,6), in which the redox polymerization was inhibited by hydroquinone (Run 6). Molecular weight of the polymer decreased under air as seen in Table VI.

\section{Copolymerization with Styrene}

Copolymerization provides us useful information to elucidate the mechanism of polymerization. An attempt to copolymerize MMA with styrene using BSA resulted in formation of only a trace amount of polymer, indicating that the copolymerization is difficult to take place. This observation is quite different from that in radical polymerization and can be explained as follows: the anionic propagating styrene end formed by alteration of the chain end is quite unstable compared to the MMA end, which is a rather stable resonance hybrid of enolate extreme; consequently, instanteneous termination by protonation occurs at the styrene end yielding telomers. Decrease of vinyl proton of the monomers was actually followed by NMR measurements, while the polymer was not obtained. These results from the copolymerization support the non-radical mechanism that was previously reported $^{9}$ and revised in this paper.

\section{CONCLUSION}

MMA was polymerized with arylsulfinic acids such as BSA. The experimental results suggest a non-radical mechanism for the polymerization, in which the initiation occurs via a Michael-type addition of BSA to MMA and the propagation proceeds via a process similar to that of zwitterion polymerization. The kinetics is compatible with the assumed mechanism.

\section{REFERENCES}

1. Farbenfabriken Bayer A.-G., Neth. Appl. Patent 6,607,951 (1966); Chem. Abstr., 66, 105818p (1967).

2. H. Kitagawa, Japan Patent 16,066 (1967); Chem. Abstr., 67, 118014u (1967).

3. Kuraray Co., Ltd., Jpn. Kokai Tokkyo Koho JP 60 45,510 (1985); Chem. Abstr., 103, 59342m (1985).

4. O. Hagger, Helv. Chim. Acta, 31, 1624 (1948).

5. C. S. Marvel and N. A. Meinhardt, J. Polym. Sci., 6, 733 (1951).

6. Y. Hachihama, H. Sumitomo, and J. Okabe, Kogyo Kagaku Zasshi, 56, 25 (1953); Chem. Abstr., 48, 7989d (1954).

7. C. G. Overberger and J. J. Godfrey, J. Polym. Sci., 40, 179 (1959).

8. G. M. Brauer and F. R. Burns, J. Polym. Sci., 19, 311 (1956).

9. T. Watanabe, K. Sakai, T. Ogata, and M. Takeishi, Polym. J., 27, 969 (1995).

10. I. Matsuda, K. Akiyama, T. Toyoshima, S. Kato, and M. Mizuta, Bull. Chem. Soc. Jpn., 48, 3675 (1975).

11. R. K. Burkhard, D. E. Sellers, F. DeCou, and J. L. Lambert, J. Org. Chem., 24, 767 (1959).

12. E. Arancibia, J. Grotewold, E. A. Lissi, and A. E. Villa, J. Polym. Sci., 7, 3430 (1969).

13. J. Grotewold, E. A. Lissi, and A. E. Villa, J. Polym. Sci., 6, 3157 (1968).

14. S. Kanno and M. Takeishi, unpublished data.

15. H. Kamogawa, H. Inoue, H. Fukuyama, and M. Nanasawa, Bull. Chem. Soc. Jpn., 52, 3010 (1979).

16. M. Takeishi, N. Iwasaki, A. Sone, Y. Chisaka, K. Sekiya, and R. Sato, Polym. Intern., 30, 73 (1993).

17. I. Matsuda, K. Akiyama, T. Kobayashi, T. Katada, and M. Mizuta, Nippon KagakuKaishi, 405 (1981); Chem. Abstr., 95, 6058h (1981).

18. H. Kamogawa, H. Kusaka, and M. Nanasawa, Bull. Chem. Soc. Jpn., 53, 3379 (1980).

19. D. Vofsi and A. Katchalsky, J. Polym. Sci., 26, 127 (1957).

20. D. S. Johnston, Adv. Polym. Sci., 42, 51 (1982).

21. J. Grodzinsky, A. Katchalsky, and D. Vofsi, Makromol. Chem., 44-46, 591 (1961).

22. J. Barton and E. Borsig, "Complex in Free-Radical Polymerization," Elsevier, Amsterdam, 1988, p 148. 